\title{
Vibration Analysis of Perforated Plates Using Time-Average Digital Speckle Pattern Interferometry
}

\author{
G.G. Romero • E.E. Alanís • C.C. Martínez • \\ L.G. Nallim • M.W. Toledo $\cdot$ L. Álvarez
}

Published online: 9 February 2010

(C) Society for Experimental Mechanics 2010

Erratum to: Experimental Mechanics

DOI 10.1007/s11340-009-9296-8

There are two errors within the References of this paper:

Reference No. 8:

Harabovsky M, Smid O, Horváth P, Baca Z (2002) Measurement of object vibrations using the theory of speckle pattern decorrelation. Optik 113(3):117-120

The correct forms of the names and surnames of authors are the following:

"Hrabovsky M" and not "Harabovsky"

"Smid P" and not "Smid O"

The online version of the original article can be found at http://dx.doi. org/10.1007/s11340-009-9296-8.

G.G. Romero $(\square) \cdot$ E.E. Alanís

Facultad de Ciencias Exactas-Grupo de Óptica Láser,

CIUNSa-Universidad Nacional de Salta,

Av. Bolivia 5150,

4400 Salta, Argentina

e-mail: marigra@unsa.edu.ar

e-mail: romeropelayog@gmail.com

C.C. Martínez

Facultad de Ciencias Naturales-Grupo de Óptica Láser, CIUNSa-Universidad Nacional de Salta,

Av. Bolivia 5150,

4400 Salta, Argentina

L.G. Nallim • M.W. Toledo · L. Álvarez

Facultad de Ingeniería, Universidad Nacional de Salta,

Av. Bolivia 5150,

4400 Salta, Argentina 